\title{
Potential effect of $\beta$ thalassemia major on cardiac function among patients in Jeddah, Saudi Arabia
}

\author{
Mohamed Nabil Alama ${ }^{1 *}$, Salwa Hindawi², Fatin El Sayes ${ }^{2}$, Samy Marouf ${ }^{3}$, Ghazi A. Damanhouri ${ }^{2}$ and Gamal I. A. Karrouf ${ }^{4 *}$ \\ ${ }^{1}$ Consultant Adult Interventional Cardiologist, King Abdulaziz University Hospital, Faculty of Medicine, King Abdulaziz University, Saudi Arabia \\ ${ }^{2}$ Department of Hematology, Faculty of Medicine, King Abdulaziz University Hospital, Saudi Arabia \\ ${ }^{3}$ Department of Clinical Pathology, Faculty of Medicine, Mansoura University, Egypt \\ ${ }^{4}$ Faculty of Science, Medical Physics Department, King Abdulaziz University, Saudi Arabia
}

\begin{abstract}
The present studydetect the prevalence of cardiac complications and the efficacy of iron overload monitoring by ECHO (LVEF), and serum ferritin assay in patients at Department of Clinical Hematology with $\beta$ thalassemia major ( $\beta$ TM). Case records of all $\beta$ TM patients were analyzed for clinical data, age, sex, heart failure, serum ferritin, ECG, chest x-ray and echocardiography. Sixty - two $\beta$ TM patients with serially recorded LVEF are included in statistical analysis. Age range of these patients was 4-36 years. Clinical congestive cardiac failure (CHF) was observed in 5 patients $(6.45 \%)$ with the age range of $13-28$ years, 34 patients $(54.8 \%)$ have normal ECHO findings while 28 patients $(45.2 \%)$ have valvular heart disease, 8 patients $(12.6 \%)$ had tricuspid regurgitation with pulmonary hypertension, and 20 patients (32.2\%) had tricuspid, mitral or aortic regurgitation. The present study indicated that Observation of excess iron in the heart of $\beta$ TM patients in King Abdulaziz University Hospital (KAUH) through LVEF and serum ferritin analysis have reduced incidence of CHF. LVEF instructs the use of intensive chelation therapy but cannot prevent or predict heart damage or $\mathrm{CHF}$ in the course of the disease; this may be due to the poor prognosis once $\mathrm{CHF}$ is occurred. More sensitive methods for early detection of cardiac complication arerequired as MRI T2* which is used to estimate myocardial iron and identifies pre-clinical cardiac iron deposition to prevent irreversible cardiac complication.
\end{abstract}

\section{Introduction}

Transfusions of blood and therapy with chelating iron has significantly increased the survival and decreased the morbidity in $\beta$ TM. However, complications of heart remain constitute a significant morbidity and remain the reason of mortality in blood transfusion in patients with $\beta$ TM [1]. $80 \%$ of patients had died by the age of 16 in the 1960 's [2] and now at least $80 \%$ survive beyond the age of 40 years but congestive cardiac failure (CHF), arrhythmias and premature deaths continue to occurred [3]. Some cases showed this was because of the difficulty in chelation treatment compliance, which was cumbersome [4], but also occurred even in some patients with well chelation therapy [5]. So, in all patients with $\beta$ TM, regular evaluation of cardiac function is recommended [6] and is now an integral part of their management. However, the value of cardiac function monitoring by Echo Cardiology to the long-term management of $\beta \mathrm{TM}$ is unclear. This is partly because the prognostic significance abnormalities of diastolic pressure, which clear early in the disease process, are unknown [7]. Additionally, CHF is often already present by the time systolic abnormalities have become manifest using Echocardiography [8]. These manifestations have led some researcher to question the value of noninvasive monitoring of cardiac function in the thalassemia management [9]. Although recovery is possible in a proportion of patients with established CHF but longterm prognosis remains poor [10,11]. Monitoring of cardiac function should clearly identify patients athighest risk ofdecompensation of cardiac function before development of CHF.

Assessment myocardial iron and function by MRI has revolutionized the treatment of $\beta$ TM patients and allows recognition of preclinical myocardial iron, stratifies prospective cardiac risk, and tracks response to modifications in iron chelation therapy [12]. This triggered us to evaluate the protocol applied in KAUH where the sequential quantification of ventricular function annually and in association with serum ferritin assay every 3 months is usedto identify early changes in the left ventricular ejection fraction (LVEF) from baseline for each patient which could be used for identifying patients at high risk and indicate the need for intensive chelation therapy.

In this study we estimated the frequency of cardiac complication and $\mathrm{CHF}$ in patients with $\beta$ thalassemia major ( $\beta \mathrm{TM}$ ) in KAUH hospitalto evaluate the efficacy of regular monitoring of cardiac function and iron overload by echocardiography, LVEF, and serum ferritin.

\section{Methods}

This study included retrospective analysis of clinical records of 62 patients from 140 patients with $\beta \mathrm{TM}$ followed up in the Clinical Hematology Department, King Abdulaziz University Hospital, Jeddah, Saudi Arabia between June 2003 and August 2010. We excluded 38 patients who do not have follow up results of Echo Cardiology. The result of Echo Cardiology, LVEF, and serum ferritin are available for 62 of 140 patients for whom the predictive value of LVEF monitoring is

Correspondence to: Prof. Gamal I. A. Karrouf, Ph.D, Faculty of Science, Medical Physics Department, King Abdulaziz University, P.O.Box:80216, Jeddah 21589, Saudi Arabia, Tel: +966595859168, Fax: 0096626952076, E-mail: drgamalkarrouf1966@gmail.com

Key words: heart failure, iron overload, $\beta$ thalassaemia major

Received: May 25, 2017; Accepted: June 26, 2017; Published: June 29, 2017 
analyzed. Thirty seven patients were men and 25 women, and the mean age was $19.5 \pm 7.3$ years (range, 4 -36 years). All patients underwent regular transfusions to maintain pre-transfusion hemoglobin levels higher than $9.5 \mathrm{~g} / \mathrm{dL}$.

Routine cardiac evaluation consisted of a detailed clinical history, physical examination, electro cardiography (ECG), and echocardiography. Impaired left ventricular (LV) function was defined as a decrease in resting LVEF either to a value below the lower reference limits of $45 \%$ or by more than $10 \%$ between 2 consecutive measurements, regardless of the LVEF value. Five patients had evidence of CHF during the period of observation (LVEF less than 45\%) and later on died from CHF.

Chelation therapy was performed exclusively with deferoxamine mesylate (DFO), which consisted of a standard regimen $(30-50 \mathrm{mg} / \mathrm{kg}$ per day by subcutaneous infusion $8-12 \mathrm{~h} / \mathrm{d}, 5-7 \mathrm{~d} / \mathrm{wk}$ ). DFO treatment was intensified in the event of objective evidence of asymptomatic $\mathrm{LV}$ dysfunction at rest to prevent progression to frank $\mathrm{CHF}$ or in case of CHF. Treatment was intensified using 24-hour continuous intravenous infusion of DFO (100 mg/kg) diluted in 500 to $1000 \mathrm{~mL}$ normal saline and delivered though a peripheral vein [13] for up to 1 week at a time to supplement ongoing subcutaneous treatment. Dosing intensification was reduced as serum ferritin values decreased in line with the therapeutic index, as previously describe [13].

\section{Outcome measures and statistical analysis}

The recorded variables were $\mathrm{CHF}$ and defined by the criteria of the Task Force on Heart Failure of the European Society of Cardiology [14]. To examine the relationship between serum ferritin concentration and cardiac risk, we divided the patients into 2 groups using the risk stratification criteria identified by Olivieri et al. [7] This analysis examines the effect of consistently high ferritin values (higher than $2500 \mathrm{~g} / \mathrm{L}$ ) on at least two occasions on survival. Summary data are presented as median or as mean \pm SD. Pearson $\mathrm{X}^{2}$ and Fisher exact tests were used to test the relationship between categorical variables. Differences between means of samples were analyzed using paired $t$ tests. All statistical analyses were performed using SPSS software.

\section{Results}

Table 1 shows that cardiac complications have occurred in $(53.2$ $\%)$ of $\beta$ TM patients but it caused only CHF and decreased LVEF less than $45 \%$ in $(6.45 \%)$. Table 2 shows that the outcome was significantly higherin those patients who maintained serum ferritin values lower than $2500 \mathrm{~g} / \mathrm{L}$ than patients their serum ferritin values higher than $2500 \mathrm{~g} / \mathrm{L}(\mathrm{P}=0.05)$. The risk for death from iron overload was also significantly increased in this group $(p=0.001)$. Age and sex showed no effect on the incidence of CHF and mortality in thalassemia patients $(\mathrm{P}>0.05)$.

Table 1. Incidence of cardiac complication in $\beta$ thalassemia patients.

\begin{tabular}{|l|c|}
\hline B halassemia patients & 62 \\
\hline Normal cardiac function & $29(54.8 \%)$ \\
\hline Abnormal cardiac function & $33(53.2 \%)$ \\
\hline CHF & $5(6.45 \%)$ \\
\hline Valvular Heart Disease & $28(53.2 \%)$ \\
\hline Tricuspid regurgitation with pulmonary hypertension & $8(12.6 \%)$ \\
\hline $\begin{array}{l}\text { Tricuspid, mitral or aortic regurigation without pulmonary } \\
\text { hypertension. }\end{array}$ & $20(24.1 \%)$ \\
\hline LVEF more than $45 \%$ & $57(91.9 \%)$ \\
\hline LVEF lessthan $45 \%$ & $5(8.1 \%)$ \\
\hline
\end{tabular}

Table 2. Relationship between risk factors and cardiac complications.

\begin{tabular}{|c|c|c|c|c|c|}
\hline \multirow[t]{2}{*}{ Variables } & \multirow{2}{*}{$\begin{array}{c}\text { No. of } \\
\text { patients } 62\end{array}$} & \multicolumn{2}{|c|}{ CHF } & \multirow[t]{2}{*}{ Dead } & \multirow[t]{2}{*}{ Alive } \\
\hline & & Yes & No & & \\
\hline Age & 62 & $5(8.1 \%)$ & $57(91.9 \%)$ & $4(6.5 \%)$ & $58(93.5 \%)$ \\
\hline Age(less than 15y.) & $15(24.2 \%)$ & $1(6.6 \%)$ & $14(93.3 \%)$ & $1(6.6 \%)$ & $14(93.3 \%)$ \\
\hline Age( more than 15y.) & $47(75.8 \%)$ & $4(8.5 \%)$ & $43(91.5 \%)$ & $3(6.4 \%)$ & $44(93.6 \%)$ \\
\hline \multicolumn{2}{|l|}{ Fisher exact test } & \multicolumn{2}{|c|}{0.62} & \multicolumn{2}{|c|}{0.86} \\
\hline Sex (male) & $37(59.7 \%)$ & $3(8.1 \%)$ & $34(91.9 \%)$ & $2(5.4 \%)$ & $35(94.6 \%)$ \\
\hline Sex (female) & $25(40.3 \%)$ & $3(12 \%)$ & $22(88 \%)$ & $2(8 \%)$ & $23(92 \%)$ \\
\hline \multicolumn{2}{|l|}{ Fisher exact test } & \multicolumn{2}{|c|}{0.463} & \multicolumn{2}{|c|}{0.53} \\
\hline LVEF $<45 \%$ & 5 & $5(100 \%)$ & 0 & $4(20 \%)$ & $1(80 \%)$ \\
\hline $\mathrm{LVEF} \geq 45 \%$ & 57 & 0 & $57(100 \%)$ & 0 & $57(100 \%)$ \\
\hline \multicolumn{2}{|l|}{ Fisher exact test } & \multicolumn{2}{|c|}{0.001} & \multicolumn{2}{|c|}{0.001} \\
\hline S.ferritin $>2500 \mathrm{ug} / 1$ & 43 & $5(11.6 \%)$ & $38(88.4 \%)$ & $4(9.3 \%)$ & $39(90.7 \%)$ \\
\hline S.ferritin $<2500 \mathrm{ug} / 1$ & 18 & 0 & $19(100) \%$ & 0 & $18(100) \%$ \\
\hline \multicolumn{2}{|l|}{ Fisher exact test } & \multicolumn{2}{|c|}{0.05} & \multicolumn{2}{|c|}{0.05} \\
\hline
\end{tabular}

\section{Discussion}

In our group of patients, LVEF performed with ECHO and serum ferritin was the regular tools for monitoring and adjusting therapy. This approach was not set up through a formal, prospective study; consequently, there is heterogeneity in patients' follow-up times and prior chelation histories. It is clear, however, that the incidence of HF is $(6.45 \%)$ suggesting that this approach is useful. Our findings show that, using LVEF, a decrease in LVEF of more thanan absolute value below the reference rangeis associated with progression to clinical heart failure and death if DFO intensification is not achieved. In 4 patients it was not clear that detectable changes in systolic function by ECHO cardiography precede the development of clinical heart failure sufficiently early for a useful intervention strategy to be adopted. Inonepatient in the present study, LVEF changes were demonstrable before cardiac symptoms appeared.

Our findings may underestimate the effectiveness of the strategy used for LVEF monitoring and treatment intensification because in the older patients, baseline LVEF values were not obtained during childhood or early adolescence. Thus, a decrease in LVEF of $10 \%$ or more from the true baseline value could not be followed accurately, and intensification might have been delayed. However this protocol has given survival to some patients till the age of 34 years. These data reflect the effectiveness of DFO therapy when used in a centre in which monitoring and intervention are given high priority. However, the optimal age at which monitoring of ventricular function should best arted remains unclear. In the prechelation-era study by Engle et al. [2] the first signs of cardiac involvement emerged at approximately 10 years of age, with patients becoming symptomatic inmiddle to late adolescence. In our study, the 5 patient who had a LVEF of $<45 \%$, had initial normal LVEF and above 10 years. We suggest that yearly quantitative LVEF monitoring of patients hould begin ideally by 10 years of age.

In our study we found that the current protocol give decrease heart failure and this is contrary to Giardina et al. 1985 [13] who showed that monitoring of LV systolic function in thalassemia was traditionally considered of limited value because changes were only demonstrable as late events using echocardiography and is heavily dependenton operator skill [14]. This can be explained as the earliest echocardio graphic studies were conducted before current standard subcutaneous and intensive intravenous DFO regimens were available that used neither chelation nor sub therapeutic doses of DFO [13]. 
From this study we conclude that LVEF measurement associated with serum ferritin assay decreased incidence of CHF in patients with $\beta$ TM in our hospital as it directs the use of intensive chelation therapy. However, LVEF by ECHO could not predict or prevent heart damage or CHF in the course of the disease; this may be due to the poor prognosis once CHF is occurred. Therefore, a new technique is recommended to be applied in our hospital as MRI which also used to estimate myocardial iron and identifies pre-clinical cardiac iron deposition $[15,16]$.

So from this study we recommend the use of cardiac $\mathrm{T} 2{ }^{*}$ in the treatment of $\beta \mathrm{TM}$ patients as it allows preclinical recognition of myocardial iron, stratifies prospective cardiac risk, and tracks response to modifications in iron chelation therapy. Use of cardiac $\mathrm{T}^{*}$ for the early identification and treatment of patients at risk is a legitimate means towards reducing the high burden of cardiac mortality.

\section{References}

1. Modell B, Khan M, Darlison M (2000) Survival in beta-thalassaemia major in the UK: data from the UK Thalassaemia Register. Lancet 355: 2051-2052.[Crossref]

2. Borgna-Pignatti C, Galanello R (2004) Thalassemias and related disorders: quantitative disorders of hemoglobin synthesis. In: Wintrobe's Clinical Hematology, Vol 42 , (11 ${ }^{\text {th }}$ edn). Lippincott Williams \& Wilkins Philadelphia:1319-1365.

3. Davis BA, Sullivan C, Jarritt PH, Porter JB (2004) Value ofsequential monitoring of left ventricular ejection fractionin the management of thalassemia major. Blood 104: 2639. [Crossref]

4. Caro JJ, Ward A, Green TC, Huybrechts K, Arana A, et al. (2002) Impact of thalassemia major on patients and their families. Acta Haematol 107: 150-157.[Crossref]

5. Aessopos A, Farmakis D, Hatziliami A, Fragodimitri C, Karabatsos F, et al. (2004) Cardiac status in well-treated patients with thalassemia major. Eur J Haematol 73: 359366.[Crossref]

6. Aessopos A, Farmakis D, Hatziliami A, Fragodimitri C, Karabatsos F, et al. (2004) Cardiac status in well-treated patients with thalassemia major. Eur J Haematol 73: 359366.[Crossref]

7. Porter JB, Davis BA (2002) Monitoring chelation therapy to achieve optimal outcome in the treatment of thalassaemia. Best Pract Res Clin Haematol 15: 329-368.[Crossref]
8. Yaprak I, Akşit S, Oztürk C, Bakiler AR, Dorak C, et al. (1998) Left ventricular diastolic abnormalities in children with beta-thalassemia major: a Doppler echocardiographic study. Turk J Pediatr 40: 201-209.[Crossref]

9. Yaprak I, Akşit S, Oztürk C, Bakiler AR, Dorak C, et al. (1998) Left ventricular diastolic abnormalities in children with beta-thalassemia major: a Doppler echocardiographic study. Turk J Pediatr 40: 201-209.[Crossref]

10. Davis BA, O'Sullivan C, Jarritt PH, Porter JB (2004) Value of sequential monitoring of left ventricular ejection fraction in the management of thalassemia major. Blood 104 263-269.[Crossref]

11. Borow KM, PropperR, Bierman FZ, Grady S, Inati A (1982) The left ventricular end-systolic pressuredimension relation in patients with thalassemia major: a new noninvasive method for assessing contractile state. Circulation 66: 980-985.[Crossref]

12. Miskin H, Yaniv I, Berant M, Hershko C, Tamary H (2003) Reversal of cardiac complications in thalassemia major by long-term intermittent daily intensive iron chelation. Eur J Haematol 70: 398-403.[Crossref]

13. Miskin H, Yaniv I, Berant M, Hershko C, Tamary H (2003) Reversal of cardiac complications in thalassemia major by long-term intermittent daily intensive iron chelation. Eur J Haematol 70: 398-403.[Crossref]

14. Kremastinos DT, Tsetsos GA, Tsiapras DP, Karavolias GK, Ladis VA, et al. (2001) Heart failure in beta thalassemia: a 5-year follow-up study. Am J Med 111: 349-354. [Crossref]

15. John C Wood, Leila Noetzli (2010) Cardiovascular MRI in thalassemia major Annals of the New York Academy of Sciences 1202: 173-179.

16. Giardina PJ, Ehlers KH, Engle MA, Grady RW, Hilgartner MW (1985) The effect of subcutaneous deferoxamine on the cardiac profile of thalassemia major: a five-year study. Ann N Y Acad Sci 445:282-292.[Crossref]

17. Himelman RB, Cassidy MM, Landzberg JS, Schiller NB (1988) Reproducibility of quantitative two-dimensional echocardiography. Am Heart J 115: 425-431.[Crossref]

18. Anderson LJ, Holden S, Davis B, et al. (2001) Cardiovascular T2-star (T2*) magnetic resonance for the early diagnosis of myocardial iron overload. Eur Heart $J$ 22: 2171 2179. [Crossref]

19. Jensen PD, Jensen FT, Christensen T, Eiskjaer H, Baandrup U, et al. (2003) Evaluation of myocardial iron by magnetic resonance imaging during iron chelation therapy with deferrioxamine: indication of close relation between myocardial iron content and chelatable iron pool. Blood 101: 4632-4639.[Crossref]

Copyright: (C2017 Alama MN. This is an open-access article distributed under the terms of the Creative Commons Attribution License, which permits unrestricted use, distribution, and reproduction in any medium, provided the original author and source are credited. 